\title{
ESPACIOS RELIGIOSOS E INFLUENCIA POLÍTICA EN LA CORTE ESPAÑOLA: EL MONASTERIO DE LA ENCARNACIÓN Y MARIANA DE SAN JOSÉ $(1616-1638)^{*}$
}

\author{
POR \\ AlejandRa Franganillo ÁlVAREZ ${ }^{1}$ \\ Universidad Complutense de Madrid
}

\section{RESUMEN}

En los últimos años, distintas publicaciones han demostrado que el convento de las Descalzas Reales de Madrid funcionó como un punto de encuentro de naturaleza política entre embajadores de distintas cortes y mujeres de la dinastía Habsburgo. No obstante, este caso no fue excepcional. El presente trabajo se propone analizar el monasterio de la Encarnación como espacio de intercambio político durante los reinados de Felipe III y Felipe IV, profundizando además en la excepcional figura de Mariana de San José, priora de la Encarnación desde 1616 hasta su muerte en 1638. Para lograrlo se ha estudiado la correspondencia perteneciente a la priora, incorporando la información proporcionada por los embajadores de diversas cortes italianas. Ello ha permitido contextualizar la participación de Mariana de San José en las pugnas cortesanas, así como valorar la rivalidad que la Encarnación mantuvo con las Descalzas Reales.

PALABRAS CLAVE: La Encarnación; Corte; redes epistolares; Felipe III; Felipe IV; patronazgo; mujeres.

\section{RELIGIOUS SPACES AND POLITICAL INFLUENCE AT THE SPANISH COURT: THE MONASTERY OF LA ENCARNACIÓN AND MARIANA DE SAN JOSÉ (1616-1638)}

\begin{abstract}
In the last years, several studies have proved how the convent of the Descalzas Reales in Madrid acted as a center of political exchange between ambassadors from other states and Habsburg women. However, it was not an exceptional case. The goal of this essay is to analyze the convent of the Encarnación as a privilege space of political exchange during the reigns of Philip III and Philip IV of Spain. On the other hand, we will focus on the extraordinary figure of Mariana de San José, the first Encarnación's prioress from 1616 to 1638 , date of her own death. In order to do that, we will study the Mariana's personal correspondence and the information provided by the ambassadors from Italian courts. This allowed us discover the significant role that Mariana played at the court of Madrid, and clarify the competition between the Descalzas Reales and the Encarnación.
\end{abstract}

KEY WORDS: The Encarnación monastery; Court; correspondence networks; Philip III; Philip IV; patronage; women.

CÓMO CITAR ESTE ARTícUlO / CITATION: Franganillo Álvarez, Alejandra. 2021. «Espacios religiosos e influencia política en la Corte española: el monasterio de la Encarnación y Mariana de San José (1616-1638)». Hispania Sacra LXXIII, 148: 457-468. https:// doi.org/10.3989/hs.2021.035

$\begin{array}{ll}\text { Recibido/Received } & 28-05-2020 \\ \text { Aceptado/Accepted } & 21-12-2020\end{array}$

\footnotetext{
Esta investigación ha sido posible gracias al disfrute de un contrato posdoctoral de Atracción de Talento Investigador-Comunidad de Madrid (Modalidad 2), ref. 2018T2/HUM10131, así como a la pertenencia al proyecto del MINECO «Adversa fortuna. Las élites ibéricas en la encrucijada (1516-1724). Desafíos, oportunidades y estrategias en la gestión del fracaso» (PID2019-106575RB-I00); y al Grupo de Investigación financiado por la Universidad Complutense de Madrid «Élites y agentes en la Monarquía Hispánica: Formas de articulación política, negociación y patronazgo (1506-1725)" (GR 105/18). Estoy en deuda por los generosos comentarios de Anne Cruz, Carmen Sanz, Sergio Ramiro y Antonio López Anguita, los cuales han contribuido a mejorar el presente texto.

2 alejandrafranganillo@ucm.es / ORCID iD: https://orcid.org/0000-0002-5185-4394
} 


\section{INTRODUCCIÓN}

En los últimos años no ha cesado el interés que especialistas procedentes de distintas disciplinas - filólogos, historiadores e historiadores del arte- han dedicado a las prácticas de escritura de las mujeres que habitaron en conventos de la Europa moderna, como ponen de manifiesto los trabajos de Poutrin (1995), Zarri (1999) o Baranda y Marín (2014), entre otros. Si bien es cierto que gran parte de estos estudios se han focalizado en las obras de naturaleza religiosa - crónicas, biografías y autobiografías (Marcos Sánchez 2018) - que elaboraron estas mujeres, otros han profundizado en aspectos vinculados a la correspondencia desarrollada por las mismas (Lavrín 1995; Castillo Gómez 2014). Uno de los numerosos ejemplos del éxito del que goza actualmente el análisis de los espacios religiosos femeninos lo constituye la exposición que ha acogido el Palacio Real de Madrid entre diciembre de 2019 y enero de 2021, relativa a la funcionalidad de las Descalzas Reales y la Encarnación como cortes femeninas complementarias a la establecida en el Alcázar. ${ }^{2}$

Gracias al estudio pionero de Magdalena Sánchez (1998) sabemos que el convento-palacio las Descalzas Reales de Madrid funcionó como un espacio contrario al privado de Felipe III, el I duque de Lerma Francisco Gómez de Sandoval. En su interior operó un grupo configurado por tres mujeres: la emperatriz María hermana de Felipe II; la hija pequeña de esta que en 1585 profesó en el convento como sor Margarita de la Cruz; y la reina Margarita de Austria. Los encuentros femeninos pertenecientes a la dinastía Habsburgo en las Descalzas Reales se remontan al momento de su fundación -gracias a la princesa Juana de Austria- en 1559 (Toajas Roger 2016), intensificándose en las décadas finales del reinado de Felipe II, como recientemente han puesto de manifiesto Magdalena Sánchez (2009) y Elisa García Prieto (2016). La influencia de estas féminas venía determinada por la consideración que sus coetáneos tenían de su influencia, derivada de la constante presencia de los monarcas, pues sor Margarita de la Cruz y su madre eran respectivamente prima y tía de Felipe III. Tras la muerte de la emperatriz María (1603) y de la reina Margarita (1611), sor Margarita de la Cruz continuó favoreciendo los intereses de la familia imperial hasta su propia muerte en 1633 (Álvarez 1971, 206-210). Según el embajador saboyano, el rey Felipe III le pidió a su hijo antes de fallecer que siguiese los consejos de sor Margarita, ${ }^{3}$ solicitud que el futuro Felipe IV cumpliría sobradamente si atendemos a las asiduas visitas que realizó al convento acompañado de la reina Isabel de Borbón, de sus hermanos y posteriormente de sus hijos. ${ }^{4}$

Al igual que sucedió con las Descalzas Reales, desde el momento de su fundación el monasterio de la Encarnación se convirtió en un espacio religioso femenino de referencia. Si en el primero la hija de la emperatriz María se citaba con el embajador alemán para conseguir que Felipe III apoyase

El resultado ha sido el catálogo de exposición editado por Checa Cremades 2019. Abreviaturas utilizadas: ASTo=Archivio di Stato di Torino; ASV=Archivio Segreto Vaticano; AGS=Archivo General de Simancas; $A S F=$ Archivio di Stato di Firenze.

ASTo, Lettere Ministri, Spagna, mazzo 17, Lettere di Germonio Anastasio, 14 de abril de 1621.

4 ASTo, Lettere Ministri, Spagna, 17, lettere di Germonio Anastasio arcivescono di Tarantasia, Madrid, 10 de febrero de 1620. los intereses políticos del Imperio, ${ }^{5}$ Mariana de San José hizo lo propio con el nuncio apostólico ${ }^{6}$ y los agentes procedentes de Viena, Florencia y Turín. Y es que, a pesar de no contar con miembros de la dinastía Habsburgo en su comunidad religiosa - hasta el ingreso de una hija natural de Felipe IV en 1649-, la familia real pasaba mucho tiempo en el convento (Muñoz 1646, 372). No obstante, la Encarnación ha recibido escasa atención si lo comparamos con las numerosas investigaciones dedicadas a las Descalzas Reales. En consecuencia, el propósito de este trabajo consiste en poner el foco en este espacio religioso, así como la figura de la que se convertiría en su primera priora, Mariana de San José. Para ello hemos recurrido al análisis de su epistolario, localizado en el archivo del monasterio de la Encarnación, que se compone de 226 cartas escritas por la agustina recoleta y 41 destinadas a ella recientemente editadas por Díez Rastrilla (2014). ${ }^{7}$ Aunque algunos aspectos de este epistolario ya han sido estudiados - como la naturaleza espiritual y cotidiana (Sánchez Hernández 2011) - , en las páginas que siguen nos interesaremos por aquellos que nos permitan reconstruir la influencia política que el monasterio y su priora ejercieron. Con el objeto de comprender mejor la figura de Mariana de San José como mediadora política, hemos favorecido la correspondencia que mantuvo con otras cortes europeas, privilegiando la toscana por la riqueza de sus fuentes. Para ello, a las cartas ya estudiadas que cruzó con María Magdalena de Austria, hemos añadido una treintena inéditas dirigidas a otras grandes duquesas: Cristina de Lorena y Vittoria della Rovere; así como al gran duque Fernando II. Por último, y a pesar de que no hemos localizado las respuestas de María Magdalena, disponemos de seis minutas de esta dirigidas a Mariana de San José que revelan su interés por consolidar una poderosa red epistolar transnacional. ${ }^{8}$

\section{EL MONASTERIO DE LA ENCARNACIÓN COMO ESPACIO POLÍTICO-RELIGIOSO}

Tras profesar a la edad de dieciocho años en el convento de Santa Cruz en Ciudad Rodrigo, Mariana Manzanedo y Maldonado (1568-1638) se trasladó a Éibar en 1603 para llevar a cabo una reforma de la orden agustina (Muñoz 1646, 371). Dos años después fundó en Medina del Campo el convento de Nuestra Señora de la Concepción; en 1606 hizo lo propio en Valladolid y en 1610 en Palencia (Sánchez Hernández 2011, 88). Durante su estancia en la ciudad del

\footnotetext{
El secretario Giulio Inghirami informaba de las frecuentes visitas que la monja recibía del nuncio apostólico y del embajador imperial. ASF, MdP, filza 4947, f. 222, carta de Giuliano Inghirami a Curzio da Picchena, Madrid, 18 de febrero de 1619. Por su parte, el embajador saboyano informa en su correspondencia ordinaria de sus visitas a las Descalzas. ASTo, lettere Ministri, Spagna, 17, lettere di Germonio Anastasio arcivescono di Tarantasia, Madrid, 23 de marzo de 1619.

6 El cardenal Pamphili daba cuenta de sus visitas a las Descalzas y a la Encarnación. ASV, Segretaria Stato Spagna, volumen 71, f. 24 Madrid, 30 de enero de 1630.

Incluyen misivas procedentes de otros archivos, como las diecinueve intercambiadas entre Mariana y María Magdalena de Austria, estudiadas por María Leticia Sánchez (2011). El resumen del contenido de cinco de estas misivas está recogido en la Bibliografía de Escritoras Españolas <http://www. bieses.net>.

8 Si bien no ha sido posible consultar en persona dichas cartas, nos consta gracias a María Leticia Sánchez que en el archivo de la En-
} carnación no se conserva ninguna misiva de María Magdalena. 
Pisuerga su labor llegó a oídos de la reina Margarita de Austria, quien le propuso que tomara las riendas del convento madrileño que planeaba fundar (Sánchez Hernández 1997; Terrasa Lozano 2014) en relación con la expulsión de los moriscos ${ }^{9}$ (Sánchez 1998, 23-25). Esta fundación constituye una de las numerosas obras pías que la reina llevó a cabo, a través de las cuales se construyó su imagen de reina devota (Guzmán 1617, 208-215; Sánchez 1998, 71-77).

Mariana de San José se convirtió en priora del monasterio de la Encarnación en 1616, momento en el que finalizó su construcción. Pese a la desaparición de Margarita de Austria cinco años antes, la presencia de Felipe III y sus hijos en la nueva fundación continuó siendo muy frecuente, tal y como documenta Luis Muñoz, autor de la biografía de Mariana (Checa Cremades 2020, 31). Esa vinculación se vio favorecida gracias a la proximidad al Alcázar, al que estaba conectado por el "pasadizo que ay en palacio», ${ }^{10}$ cuya ejecución había dispuesto Margarita de Austria en su testamento (Sánchez $1993,148)$. A través de una sucesión de galerías y salas repletas de pinturas, el pasadizo desembocaba en el Salón de Reyes - pieza cuya llave solo poseía la priora-, destinado a recibir a los monarcas, príncipes e infantes. La estancia estaba oportunamente decorada con los retratos de la familia real española (García-Frías 2019, 223) y la Toscana, entre los cuales figuraba uno de María Magdalena, hoy ubicado en el convento (Goldenberg Stoppato 2004, 180-181).

\section{FIGURA 1}

\section{Fragmento del plano anónimo "Madrid planos de población 1622-1635», editado por Johannes Janssonius, 1657}

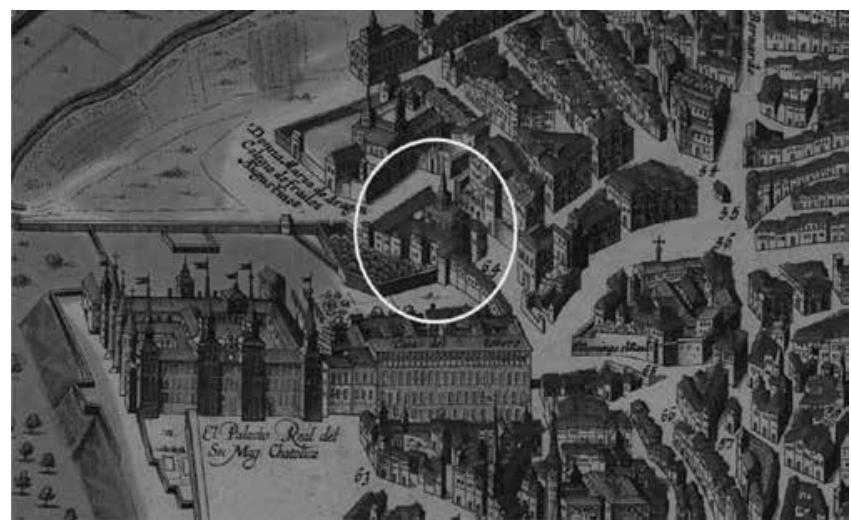

Fuente: Biblioteca Nacional de España, INVENT/68156

Junto al desempeño de sus labores como priora, Mariana de San José desarrolló un activo papel en relación a la política internacional española. Esto le permitió convertirse - junto a sor Margarita de la Cruz - en una de las mayores defensoras en Madrid de los intereses de los Habsburgo de

En su crónica, Pedro Aznar Cardona alude a esta vinculación: «En fin yo me hago a la parte de la quondam serenissima Reyna, nuestra señora, doña Margarita de Austria, que desde el Cielo nos ayuda con su patrocinio declarado contra los infieles Moros». Expulsión ivstificada de los moriscos españoles y suma de las excelencias christianas de nuestro rey $D$. Phelipe, tercedro de este nombre. Huesca: Pedro Cabarte, 1612, f. 118r. Agradezco a Anne Cruz el haberme indicado esta referencia.

10 ASF, MdP, 6083, s.f., carta de la priora de la Encarnación a la archiduquesa, Madrid, 22 enero 1617.
Viena, ${ }^{11}$ a pesar de que no le unían lazos de parentesco a la familia imperial, ni estas políticas beneficiarían a miembros de su familia, como sucedió en los casos de sor Margarita de la Cruz o Luisa de las Llagas (Marek 2011). Asimismo, Mariana se involucró en las diferentes pugnas cortesanas que sacudieron Madrid en la primera década del siglo XVII, simpatizando con el grupo contrario a Francisco Gómez de Sandoval. El cronista Matías de Novoa responsabilizó a fray Juan de Santa María y a la priora de la actitud que Margarita de Austria adoptó contraria a Lerma, pero también de la pérdida de influencia de Rodrigo Calderón (Sánchez 1998, 97). En las instrucciones que el gran duque Cosme II envió el 24 de abril de 1619 a su embajador, le advertía de las transformaciones que estaba experimentando Madrid en los últimos meses, en referencia a la salida de la corte del duque de Lerma en octubre de 1618, episodio conocido como la «revolución de las llaves» (García García 1997). En esta cambiante coyuntura, el objetivo de Giuliano de Médici debía ser averiguar quiénes eran los nuevos favoritos del rey para ganarse su confianza (Martelli y Galasso 2007, 318322). Una vez en Madrid, Giuliano detectó a las personas más próximas a Felipe III, entre las que figuraban el duque de Uceda, Baltasar de Zúñiga - tío del futuro todopoderoso Gaspar de Guzmán-; el marqués de Villafranca, el cardenal Zapata o Luis de Aliaga, confesor del monarca. A ellos añadía a varias mujeres: la condesa de Lemos - hermana del duque de Lerma-, las duquesas de Gandía y Sessa; la marquesa del Valle, y dos religiosas: sor Margarita de la Cruz y Mariana de San José. ${ }^{12}$ Unos meses después, Giuliano corroboraba la privilegiada posición de esta última: «questa monaca è donna che entra nei negozi et che parla spesso con le Maestà et con tutti i principali ministri» (Martelli y Galasso 2007, 391-395), consideración que sin embargo no procedía de la pertenencia de Mariana a la realeza ni a la nobleza, sino de su labor espiritual y de su cercanía a la familia real.

\section{LA PRIVILEGIADA RED DE CORRESPONDIENTES DE MARIANA DE SAN JOSÉ}

Gracias a las noticias que proporciona el siempre bien informado embajador toscano, podemos afirmar que la priora formaba también parte del núcleo de oposición al III duque de Osuna Pedro Téllez-Girón —virrey de Sicilia (1610-1616) y de Nápoles (1616-1620) - junto al prior de El Escorial Juan Peralta, el VIII conde de Benavente, fray Juan de Santa María, Fernando Carrillo, sor Margarita de la Cruz, todos ellos bajo la dirección de Filiberto de Saboya. ${ }^{13}$ Precisamente el príncipe saboyano fue uno de los excepcionales correspondientes que destacaron en la red epistolar que la priora tejió durante las primeras décadas del siglo XVII, en la que

11 ASF, MdP, 6083, s.f., carta de Mariana de la priora de la Encarnación a la archiduquesa, Madrid, 22 enero 1617. Mariana repetía que intercedería en su favor ante los monarcas y principales ministros: «tan sierva de V.A. como siempre lo e de ser [...] y ansí no pierdo ocasión de mostrarlo en todas las [ocasiones] que se me ofrecen, ansí con sus majestades y sus hijos como con los ministros más válidos». ASF, MdP, 6083 , s.f., carta de la priora de la Encarnación a la archiduquesa, Madrid, 11 septiembre 1618.

ASF, MdP, 4949, f. 74, Giuliano de Médici al gran duque, Madrid, 28 julio 1619.

13 ASF, MdP, 4949, f. 527, carta de Giulio Inghirami a Curzio da Picchena, Madrid, 9 agosto 1620. 
también figuraron Luisa de Carvajal y Mendoza (Cruz 2014, 66-109 y 2019), el papa Urbano VIII o el cardenal Barberini (Alonso 1988; Sánchez Hernández 2014) entre otros.

FIGURA 2

Fragmento del grabado de Quesádez, Francisco, Venerable Madre Mariana de San José, 1665

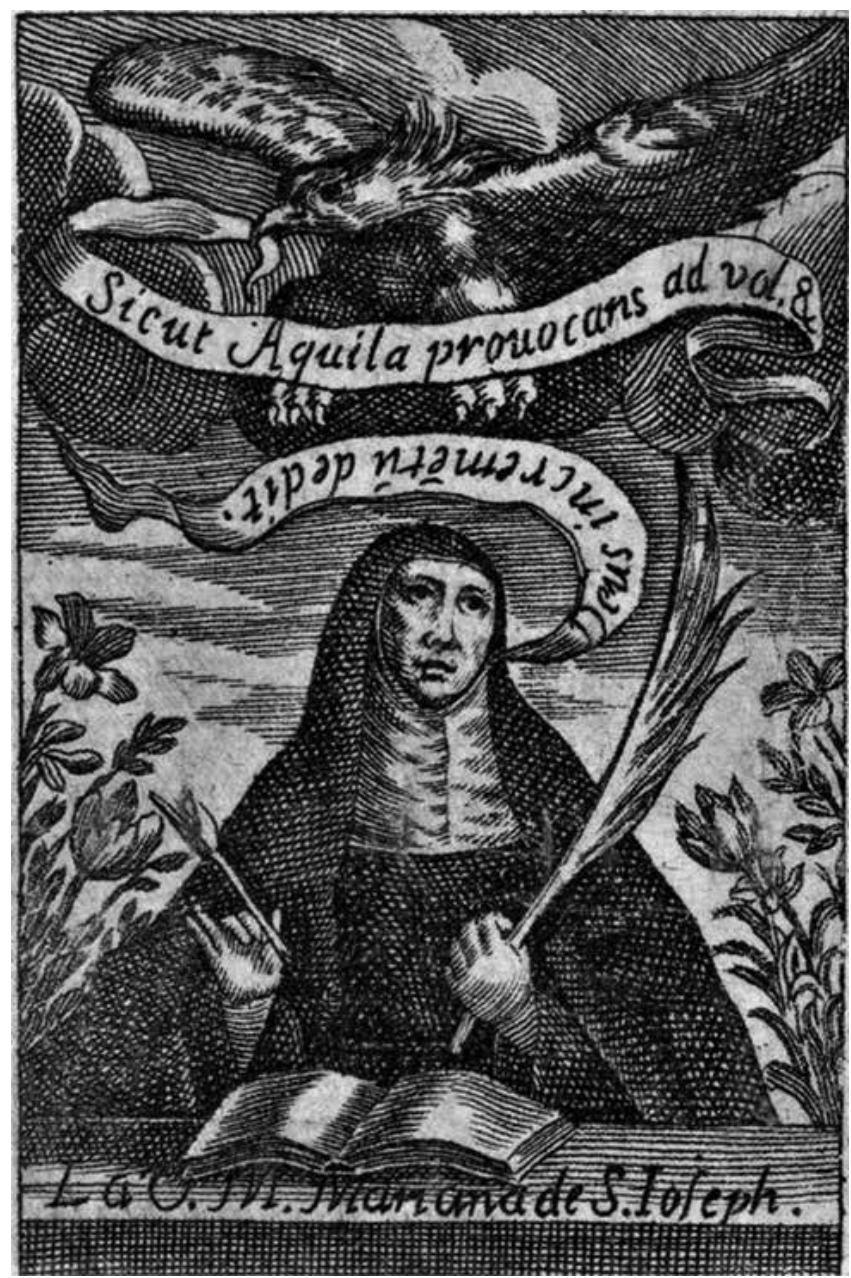

Fuente: BNE, INVENT/12848.

Tercero de los hijos del duque Carlos Manuel I y la infanta Catalina Micaela, el príncipe Manuel Filiberto de Saboya (1588-1624) viajó a Madrid en 1603 junto a sus hermanos Felipe Manuel -quien fallecería en la corte española- y Víctor Amadeo (Río Barredo 2006; Antolín Rejón 2016, 8992). Aunque tres años después regresó a Turín, en 1610 estaba de nuevo en Madrid para solicitar el perdón por el tratado de Bruzolo que su padre, Carlos Manuel I, había firmado con Enrique IV de Francia. Filiberto pronto recuperó el favor real y, en 1612, fue designado general del mar, cargo que le proporcionaba el control de la flota de la Monarquía Hispánica. ${ }^{14}$

Las veintitrés cartas de Filiberto conservadas en el convento de la Encarnación (Díez Rastrilla 2014, 1121-1149) nos permiten reconstruir la estrecha relación que mantuvo

14 Una aproximación a la trayectoria de Filiberto de Saboya la ofrece Geevers 2016. con Mariana de San José, cuya explicación radica en el interés que el joven tenía por contar con apoyos entre personas próximas al monarca. La primera misiva data del 8 de enero de 1619 y la última del 17 de junio de 1624, menos de dos meses antes de la muerte de Filiberto a consecuencia de la peste. En la primera carta el príncipe le pide a la priora que, cuando tenga ocasión, le hable a Felipe III «en la conformidad que se desea», tal y como había hecho sor Margarita de la Cruz la última vez que el monarca había visitado las Descalzas (Díez Rastrilla 2014, 1121). Recordemos que sor Margarita tenía lazos de sangre con Filiberto, y a ellos respondió la monja respaldando las aspiraciones del italiano (Anselmi 2014, 418-420). ${ }^{15}$ Aunque no sucedía lo mismo en el caso de la priora de la Encarnación, Filiberto demostró la confianza que depositó en ambas encargándoles que tratasen de contrarrestar la mala imagen que Felipe III se estaba forjando de su padre y de él mismo, como consecuencia de los capciosos comentarios que sus enemigos habían esparcido (Díez Rastrilla 2014, 1137). ${ }^{16}$ No hay género de dudas a este respecto cuando Filiberto escribe desde Turín un año después, el 13 de enero de 1620 (Díez Rastrilla 2014, 11321133), solicitándole le transmita al rey

cuán deseoso está mi padre de servir a Su Majestad [...] porque para hacer daño y deservicio a Su Majestad no faltan personas que quieren conservar desconfianza sin causa. Le aseguro a vuestra merced vivo por sus fines y provecho de Su Majestad; y lo que se habla ahí no sé qué decir a vuestra merced, lastimándome infinito que Su Majestad dé lugar a que esto sea, por los fines que se sabe que lo procuran don Pedro de Toledo $-\mathrm{y}$ fomentado por el duque de Uceda, que para esto se juntarán-y el duque de Osuna.

Su principal preocupación era la credibilidad que el rey daba a sus enemigos, representados por el grupo establecido en torno a Uceda y el confesor real, en el que destacaban el marqués de Villafranca y el III duque de Osuna. ${ }^{17}$ El 2 de abril de 1619 Filiberto le confiaba a Mariana que había advertido al rey sobre la necesidad de que destituyese a Osuna como virrey de Nápoles por lo que «convenía cuidar de lo que pasaba en el aposento del príncipe», en clara alusión a las camarillas que allí se reunían para influir en el futuro Felipe IV (Díez Rastrilla 2014, 1122-1123). Dos días después le anunciaba que Felipe III había ordenado que partiese a Italia para ejercer como General del Mar. Filiberto esperaba que la mediación de fray Juan de Santa María y de Mariana de San José mejorase su situación, junto al buen hacer de ministros como Baltasar de Zúñiga (Díez Rastrilla 2014,

15 El apoyo de sor Margarita se hacía extensible a todos los miembros de la familia Saboya, pues según el embajador toscano, ante la posibilidad de que Felipe III volviese a contraer matrimonio tras la muerte de Margarita, la monja escribió al monarca pidiéndole que priorizase entre las opciones existentes a las candidatas procedentes de la casa de Austria, Baviera o Saboya (García García 2020, 45).

16 Así lo expresa en una carta que envía desde Aranjuez el 7 de mayo de 1620: «Su Majestad me favoreció, y mostró el gusto que suele; pero, como todavía es cierto que esta gente no se descuidará de lo que desean, estoy con cuidado. Y así, vuestra merced se sirva de que, cuando haya ocasión, representar a Su Majestad el fin que les mueve».

En uno de los avisos del embajador florentino detallaba que los responsables de la marcha de Filiberto de Madrid fueron Aliaga y Uceda, quienes «habbino fatto il ponte di oro per mandarlo via». ASF, MdP, 4949, f. 664, Madrid, 28 noviembre 1620. 
1125, 1127-1128) ${ }^{18}$ o el VIII conde de Benavente (Díez Rastrilla 2014, 1139), ${ }^{19}$ todos ellos contrarios al duque de Uceda y al confesor real. En ocasiones el príncipe no es excesivamente claro en sus cartas, tal vez por miedo a que fuesen interceptadas, reservando la totalidad de la información a los agentes enviados a la Encarnación, como se desprende de la misiva que Filiberto le envió desde Chieri el 4 de diciembre de 1619 (Díez Rastrilla 2014, 1131).

Anteriormente nos hemos referido a Filiberto de Saboya como uno de los miembros más activos dentro de la oposición al duque de Uceda y a fray Luis de Aliaga, grupo en el que también participaban sor Margarita de la Cruz y Mariana de San José. Según informó en un inserto cifrado Giuliano de Médici, el confesor del rey consiguió expulsar en 1620 a Filiberto de Madrid por liderar una fallida conspiración contra él mismo y Uceda, en la que se vieron involucrados la infanta de las Descalzas, la priora de la Encarnación y fray Juan de Santa María (Elliott 2010, 130-131). ${ }^{20}$ Justo un año después, Filiberto vio la oportunidad de recuperar su favor con motivo de la muerte de Felipe III, presentándose de inmediato al Alcázar para postularse al servicio del futuro Felipe IV. Unas semanas antes de que tuviese lugar el deceso del rey, el saboyano justificó ante Mariana -en una carta fechada el 4 de marzo de 1621 - el contenido de la conversación que había mantenido con el todavía príncipe Felipe:

Sólo una vez, creo, o dos, le hablé diciéndole se estrechase mucho con su padre y le sirviese, que este era el camino para que todo fuese bien y él le pudiese descansar y ayudar en los negocios, y que esto podría ser algunos no lo deseasen [...] y que le suplicaba atender que nadie deseaba más el servicio de Su Majestad y el suyo que yo, pues mis obligaciones y amor eran tan diferentes de los demás..

Filiberto se lamentaba de que alguien hubiese transmitido a Felipe III esta conversación en otros términos con el fin de perjudicarle, y ese alguien podía ser el conde de Olivares (Díez Rastrilla 2014, 1145-1146). Según los rumores cortesanos, en la enemistad entre Filiberto y el futuro valido de Felipe IV tuvo también que ver un conflicto amoroso relacionado con el interés que ambos mostraron a Ana María Manrique, dama de la reina Isabel de Borbón. Sea como fuere, no iban muy desencaminadas las voces cortesanas en sus apreciaciones, pues una vez que Felipe IV accedió al trono, Olivares consiguió alejar a Filiberto de Madrid con la promesa del virreinato de Sicilia, cargo que finalmente obtuvo en diciembre de 1621.

Entre las personalidades más relevantes con las que Mariana tuvo relación destaca la vinculación que desarrolló con los condes-duques de Olivares. Aunque solamente se conserva una carta dirigida al valido y otra a su esposa, varios testimonios demuestran la proximidad de la priora a la pareja y el propio Díez Rastrilla $(2014,588)$ reconoce que debieron de intercambiarse más cartas, aunque no hayan llegado hasta nuestros días. Es de suponer que Inés de Zúñiga, en calidad de Camarera Mayor de Isabel de Borbón y aya

18 Cartas de Filiberto de Saboya a la priora de la Encarnación, Madrid, 4 de abril de 1619 y Cartagena, 10 de junio de 1619.

19 Carta de Filiberto de Saboya a la priora de la Encarnación, San Lorenzo de El Escorial, 9 de agosto de 1620.

20 ASF, MdP, 4949, f. 664, inserto de Giulio de Medici a Curzio da Picchena, Madrid, 28 noviembre 1620. del príncipe, acudía junto a la reina y sus hijos cuando se desplazaban a la Encarnación. Sabemos que Baltasar Carlos visitaba a la priora desde que era un bebé, y a la altura de 1631 lo hacía aproximadamente cada tres días, pues disfrutaba mucho dando de comer «las migajitas que deshace con sus manos» a unos pollos que se encontraban en el convento. ${ }^{21}$ Además de acompañar a la reina y al heredero, Inés de Zúñiga también acudía sola al convento tal y como afirma la propia Mariana en su misiva del 30 de julio de 1626 (Díez Rastrilla 2014, 836-838). Tanto es así que la esposa del valido fundó en la Encarnación dos capellanías dedicadas a la salud del príncipe (Carlos Varona 2007, 237). Este contacto permitió que entre ambas mujeres se consolidase una estrecha confianza que el nuncio apostólico calificaba de amistad en 1630: "La Sra Priora [...] e molto amica de la Sra Contessa d'Olivares». ${ }^{22} \mathrm{Y}$ es que los condes-duques de Olivares compartían intereses comunes con Mariana de San José relativos a la fundación de un convento en sus posesiones sevillanas, del que ejercieron como patronos y fundadores. Sobre esta cuestión versa un significativo porcentaje de las noventa y cinco cartas que Mariana remitió a la madre María del Espíritu Santo, estrecha colaboradora y priora del convento de Castilleja de la Cueva y posteriormente de Carmona (Díez Rastrilla 2014, 586)..$^{23}$ De esta temática trata la única carta que se conserva dirigida a Inés de Zúñiga el 8 de febrero de 1628 - respuesta a otra que había recibido de ella (Díez Rastrilla 2014, 861-862) - en la que se disculpa por no poder acudir en persona al convento a consecuencia de su falta de salud. No obstante, las frecuentes visitas de la condesa se vieron abruptamente interrumpidas con motivo de la muerte de su única hija, María de Guzmán, poco después de dar a luz a finales de julio de 1626, transcurriendo varios meses hasta que volvió a pisar el monasterio (Díez Rastrilla 2014, 845-846).

\section{LA CORRESPONDENCIA ENTRE LA PRIORA Y LA FAMILIA MÉDICI}

Nacida en Graz el 7 de octubre de 1589, María Magdalena de Austria fue uno de los quince hijos que tuvieron María de Baviera y su tío Carlos II de Habsburgo, archiduque de Austria y duque de Estiria (Galli Stampino 2013, 42). Una vez viuda, la archiduquesa María de Baviera desarrolló una ambiciosa estrategia matrimonial logrando situar a sus hijas en las principales cortes europeas: Ana y Constanza se convirtieron en esposas de Segismundo III de Polonia en 1592 y 1605; Margarita se desposó con Felipe III en 1598; y María Cristina contrajo matrimonio con el príncipe de Transilvania Segismundo Bathory (Rainer 2005, 34-37). Diez años después, los monarcas españoles favorecerían el matrimonio de María Magdalena con el heredero al Gran Ducado de Toscana, celebrado el 14 de septiembre de 1608. La pareja tuvo en común ocho hijos: cinco varones -el futuro gran duque Fernando II, Juan Carlos, Matías, Francisco y Leopoldo- y tres niñas: María Cristina - quien vivió en un monasterio

21 ASF, MdP, 5080, ff. 172-173, carta de Mariana de San José a María Magdalena Madrid, 16 de junio de 1631.

22 ASV, Segretaria Stato Spagna, 71, f. 124, Madrid, 2 de mayo de 1630 .

23 En 1634 los condes de Olivares trasladaron el convento de dominicas que habían fundado en Castilleja de la Cuesta a las tierras que habían adquirido en Loeches un año antes (Atienza 2008, 212). 
debido a su discapacidad mental-; Margarita - llamada así por su tía, y quien a partir de 1628 se convertiría duquesa de Parma tras contraer matrimonio con Odoardo Farnese- y Ana, esposa del archiduque de Austria Fernando Carlos de Habsburgo.

La muerte de Fernando I el 7 de febrero de 1609 convirtió a Cosme II y María Magdalena en los nuevos grandes duques de Toscana, período durante el cual la archiduquesa participó en la vida política aconsejando a su marido y tratando que el estado italiano brindase mayor apoyo al imperio durante la guerra de los Treinta Años. Su intervención en materias políticas se incrementaría después de la muerte de Cosme II el 28 de febrero de 1621, cuando desempeñó junto a su suegra Cristina de Lorena una regencia compartida hasta 1628, momento en el que el gran duque Fernando II alcanzó su mayoría de edad. ${ }^{24} \mathrm{Al}$ igual que su madre y el resto de sus hermanas, María Magdalena destacó por su devoción religiosa, una actitud que plasmó en la fundación de numerosas instituciones, peregrinaciones y coleccionando gran cantidad de reliquias. En este ámbito espiritual es en el que debemos contextualizar la fluida correspondencia que María Magdalena mantuvo con sor Orsola Fontebuoni, abadesa del monasterio de San Mercuriale en Pistoia (Toscana) entre 1616 y 1630, cuya fama de santidad propició que otras personalidades de la península italiana, Francia y el Imperio quisieran mantener un vínculo con ella (Belardini 1999, 361). Esta relación epistolar nos permite establecer una serie de paralelismos entre la correspondencia que María Magdalena cruzó con la priora de la Encarnación. Por ejemplo, la abadesa envió treinta y tres misivas a la gran duquesa, número muy parecido a las treinta y una que conocemos de Mariana de San José entre 1616 y 1630 (Belardini 1999, 366). Otra similitud radica en que la abadesa se carteó con otros miembros de la familia real, al igual que la priora de la Encarnación, aunque ninguna de las cartas de sor Orsola fueron escritas de su puño y letra (Belardini 1999, 367), a diferencia de las de Mariana de San José, todas ellas hológrafas.

La treintena de cartas analizadas que Mariana de San José dirigió a María Magdalena solían abarcar entre uno y dos folios por ambas caras. Las frecuentes expresiones de fidelidad empleadas por la agustina, junto a una serie de factores que desarrollaremos a continuación, nos permiten considerar a Mariana de San José como miembro integrante de las redes de patronazgo de María Magdalena de Austria. ${ }^{25}$

Desconocemos el momento exacto en el que se inicia el intercambio epistolar, si bien es posible que se produjese con anterioridad a 1617, fecha de la primera misiva de la que tenemos constancia, pues en ella la priora lamenta no recibir sus cartas. ${ }^{26}$ Gracias a las referencias que nos pro-

24 Tradicionalmente la historiografía consideró esta regencia femenina la causa de la decadencia socioeconómica del Gran Ducado. No obstante, historiadores recientes han cuestionado esta afirmación, ofreciendo hipótesis alternativas (Arrivo 2007, 50-51; Galli Stampino 2013, 44-48).

25 Para profundizar en las características del patronazgo en las cortes reales de época moderna nos remitimos a los estudios de Sharon Kettering (1986).

26 ASF, MdP, 6083, s.f., carta de la priora de la Encarnación a la archiduquesa, Madrid, 22 de enero de 1617. La misiva carece de fecha, aunque el Medici Archive Project la data en 1617 ya que iba dentro porciona el embajador de las grandes duquesas sobre sus frecuentes visitas al convento, podemos afirmar que este intercambio se consolidó e intensificó a lo largo de la década siguiente. ${ }^{27}$ La difunta reina Margarita de Austria era el nexo que compartían, lo cual explica su omnipresencia a lo largo de las más de dos décadas que duró la relación epistolar. ${ }^{28}$ La priora perteneció al reducido círculo espiritual que rodeó a la reina en vida, y que tras su muerte en 1611 escribió a su hermana María Magdalena de Austria con el objeto de jurarle fidelidad. Algunos incluso habían mantenido un intercambio epistolar con su madre, María de Baviera (Keller 2019, 151-154), entre los que figuraban el capellán Joseph Ximeno; el confesor de la reina Margarita Richard Haller, y el ayudante de este, el también jesuita Pedro Garcés (Franganillo 2019, 180-181).

Creemos que fue Mariana de San José quien tomó la iniciativa a la hora iniciar una relación epistolar. No obstante, la gran duquesa fue consciente de inmediato de las ventajas derivadas que esta relación le podía reportar a la hora de consolidar su propia posición en la Toscana (Volpini 2016, 128-130). Como esposa del gran duque y posterior regente entre 1621 y 1628 junto a su suegra Cristina de Lorena, con la que sin embargo no mantenía una excelente relación, María Magdalena puso en juego todas las herramientas de las que disponía para beneficiar los intereses de sus hijos. Llegados a este punto, resulta significativo que siempre que Mariana alude a la archiduquesa lo hace en referencia a su pertenencia a la dinastía Habsburgo, obviando su papel como gobernante de la Toscana, lo cual dice mucho acerca del sentimiento que estas mujeres mantenían respecto a sus respectivas familias de origen (Volpini 2016, 130-131). Precisamente uno de los instrumentos principales que utilizó María Magdalena para sus fines fue el de estrechar los lazos afectivos con los miembros de la familia real española. Así, solicitó a la priora por medio del embajador toscano que favoreciese una relación fluida en el rey y en sus hijos: «Díjome [el embajador] que el mayor servicio que podría hacer a Vuestra Alteza y al señor Gran Duque sería despertar en el rey nuestro señor y sus hijos la correspondencia». ${ }^{29}$ Mariana le aseguró que ya había iniciado las diligencias necesarias para que la hija de Felipe III, la infanta María - sobrina predilecta de María Magdalena - escribiese a su tía cuanto antes. En un borrador de carta de la gran duquesa, esta le informa del envío de Giuliano de Médici como nuevo embajador en Madrid, a quien había ordenado que fuese a verla en su nombre. ${ }^{30}$ Es muy similar a otra que se conserva del mismo día dirigida a sor Margarita de la Cruz, lo que

de otra de 1617 <http://bia.medici.org/DocSources/Home.do>. En la transcripción que adjunta Díez Rastrilla corresponde a 1620.

27 ASF, MdP, 4952 s.f., carta de Averardo de Medici, 16 de octubre de 1623.

28 ASF, MdP, 6083, s.f., carta de la priora de la Encarnación a la archiduquesa, Madrid, 26 septiembre 1618.

29 ASF, MdP, 6083, s.f., carta de Mariana de San José a María Magdalena, Madrid, 26 septiembre 1618.

30 ASF, MdP, 6101, f. 177, carta de María Magdalena a Mariana de San José, Florencia, 17 de julio de 1619. Se conserva otra minuta de María Magdalena en la que precisamente le notifica el regreso a Florencia de Giuliano de Médici, a quien ha ordenado que antes de marchar visitase a Mariana para asegurarle la confianza que sigue depositando en ella y el deseo de que continúe transmitiéndole informaciones del rey y sus hijos. Ibídem, f. 5, carta de María Magdalena a Mariana de San José, Florencia, 9 de septiembre de 1620. 
demuestra que la gran duquesa tenía muy presente la necesidad de cultivar buenos contactos en ambos conventos. ${ }^{31}$

Aunque, como apuntamos anteriormente, no se conservan las respuestas de María Magdalena, como ejemplo recurriremos a dos de las seis minutas que se conocen, con el propósito de reconstruir parte de la conversación a distancia mantenida entre ambas mujeres entre abril y septiembre de 1619. Empezaremos con el borrador de la carta que la gran duquesa envía el 14 de abril a la priora. Conocedora del viaje que Felipe III había emprendido junto a sus hijos a Portugal, solicita le envíe al rey recuerdos de su parte, al tiempo que aprovecha para informarle acerca de las novedades relativas a Alemania. ${ }^{32}$ La priora responde el 2 de junio avisándole de la llegada de una carta de Felipe III en la cual el monarca aseguraba que escribiría a la gran duquesa tan pronto como llegase a Lisboa. ${ }^{33}$ María Magdalena agradecía la labor de Mariana, instándole a mediados de julio a que continuase transmitiendo al rey y a los príncipes e infantes lo mucho que se acordaba de ellos. ${ }^{34}$ Por último, el 19 de septiembre Mariana respondía alegrándose de la elección de Fernando de Habsburgo - hermano de María Magdalena - como emperador, suceso que favorecería la posición de la gran duquesa. ${ }^{35}$

Tras la muerte de Margarita de Austria y de Felipe III en 1611 y 1621 respectivamente, Isabel de Borbón y Felipe IV asumieron su papel como protectores del convento de la Encarnación. Aunque no tenemos constancia de la existencia de correspondencia personal entre la reina y la agustina recoleta, se documenta la presencia continua de Isabel a través de la relación epistolar de Mariana de San José y la gran duquesa de Toscana. ${ }^{36}$ Sabemos que en 1622 la priora leía en voz alta ante la reina las misivas de María Magdalena en las que hablaba de María de Médici - la madre de Isabel de Borbón-;37 dos años después, en febrero de 1624 y durante el viaje de Felipe IV a Andalucía, incrementó la afluencia de sus visitas acudiendo dos veces por semana. ${ }^{38}$ Según su propio testimonio, Mariana de San José se ocupó personalmente de que ambos monarcas tuviesen muy presentes a los Grandes Duques de Toscana, mencionándoles en las conversaciones que mantenía con ellos. ${ }^{39}$ En una de las últimas cartas que envió a María Magdalena antes de la

31 ASF, MdP, 6101, f. 7, carta de la archiduquesa a sor Margarita de la Cruz, Florencia, 9 septiembre 1620.

32 ASF, MdP, 6101, f. 225, carta de la archiduquesa a la priora de la Encarnación, Florencia, 14 abril 1619.

33 ASF, MdP, 6083, s.f., carta de la priora de la Encarnación a la archiduquesa, Madrid, 2 junio 1619.

34 ASF, MdP, 6101, f. 177, minuta de carta de la archiduquesa a la priora de la Encarnación, Florencia, 17 julio 1619.

35 ASF, MdP, 6083, s.f., carta de la priora de la Encarnación a la archiduquesa, Madrid, 1 septiembre 1619. El hijo de Fernando, futuro emperador Fernando III, contrajo matrimonio con la hija de Felipe III, la infanta María, sobrina predilecta de María Magdalena de Austria.

36 El embajador toscano también informa de las visitas que la reina realizaba a las Descalzas durante las ausencias de su marido. ASF, MdP, 4956, f. 267, carta de Averardo de Medici, 7 noviembre 1628.

37 ASF, MdP, 4951 s.f., Madrid, 31 agosto 1622. Mariana pidió al embajador le tradujese al castellano el fragmento de la carta en la que hablaba de María de Medici para leérsela a la reina, ASF, MdP, 4958, Madrid, 16 julio 1631.

38 ASF, MdP, 6083, carta de la priora de la Encarnación a la archiduquesa, Madrid, 18 febrero 1624.

39 ASF, MdP, 6083, s.f., carta de la priora de la Encarnación a la archiduquesa, Madrid, 13 septiembre 1622. muerte de esta, le aseguraba que «muchas veces les traygo a la memoria quando vienen acá la que deben tener desa Real casa». ${ }^{40}$

La proximidad de la priora con la familia real explica su labor como intermediaria de los obsequios que los Grandes Duques enviaron al rey, príncipes e infantes durante estos años (Franganillo 2013, 137-141). Los regalos solían consistir en vestidos para la hermana del rey; unos lentes destinados a Isabel de Borbón, o juguetes para el heredero. ${ }^{41} \mathrm{Y}$ viceversa: en numerosas ocasiones la priora entregó al embajador objetos originarios de América tuyos destinatarios eran los miembros de la familia Granducal. ${ }^{42}$ Parece que en relación con esta actividad surgieron ciertos recelos entre la Mariana de San José y sor Margarita de la Cruz. El embajador toscano menciona en alguna ocasión cómo Mariana le reprochaba que la infanta de las Descalzas pudiese recibir sus ropas de altar antes de que a ella le llegaran las «niñerías» que había pedido. ${ }^{43}$ Pero los celos no solo se produjeron por parte de la agustina: en una ocasión le fue entregada por error a sor Margarita una carta que en realidad era para Mariana de San José. Cuando el secretario toscano acudió a recuperarla, la infanta "ne restò meravigliata [...] da questo s'è potuto dubitare che nascesse un poco di gelosia nella signora Infanta che la Madre Priora facesse qualche cosa ne' negozi di cotesta Serenissima Casa». ${ }^{44}$

Junto al agradecimiento que la gran duquesa expresó en sus cartas, la priora de la Encarnación recibió como recompensa objetos destinados a la decoración del convento, muchos de los cuales había solicitado expresamente ella misma: ${ }^{45}$ telas para el altar con piedras preciosas, ${ }^{46}$ retratos y pinturas religiosas. ${ }^{47}$ Parece que estas últimas constituían lo más preciado, pues aprovechó las condolencias trasladadas al gran duque Fernando II con motivo de la muerte de su madre María Magdalena para recordarle que la archiduquesa le había prometido el envío de unos cuadros de temáti-

40 ASF, MdP, 5080, ff. 172-173, carta de la priora de la Encarnación a la archiduquesa, Madrid, 16 junio 1631.

41 ASF, MdP, 4962, carta del secretario Cioli a Michelangelo Baglioni, Florencia, 24 septiembre 1630. En relación a los juegos del príncipe Baltasar Carlos, nos remitimos al reciente y excepcional estudio de Carlos Varona y Cherry 2020.

42 ASF, MdP, 4949, carta de Giuliano de Médici a la archiduquesa, Madrid, 12 marzo 1621.

${ }^{43}$ ASF, MdP, 4958, s.f., carta de Michelangelo Baglioni al secretario Cioli, Madrid, 12 abril 1631. La Priora se alegró cuando llegaron unas pinturas toscanas al convento, especialmente porque sor Margarita no había recibido ningún regalo: «stima molto di esser lei regalata et che alle Discalze non si manda niente». Ibídem, 25 de octubre de 1631.

44 ASF, MdP, 4958, s.f., carta de Bernardo Monanni al secretario Cioli, Madrid, 3 mayo 1631. Andrea Cioli advirtió al embajador que el error había sido significativo por haber desvelado la relación entre ambas mujeres, pidiéndole que le transmitiese al secretario extremar las precauciones. ASF, MdP, 4962, s.f., carta del secretario Cioli a Michelangelo Baglioni, Florencia, 11 junio 1631.

45 Así lo atestigua el propio embajador. ASF, MdP, filza 6083, carta de Orso d'Elci a María Magdalena, Madrid, 20 de enero de 1618. Al margen de objetos decorativos, destacó el envío de medicamentos. ASF, MdP, 4949, f. 363, carta de Giuliano de Medici a Giulio Inghirami, 25 de marzo de 1620.

46 ASF, MdP, 6083, s.f., carta de la priora de la Encarnación a la archiduquesa, Madrid, 13 de diciembre de 1618.

47 ASF, MdP, 4962, s.f., carta de Andrea Cioli a Esaú del Borgo, Firenze, junio 1630 
ca devocional. ${ }^{48} \mathrm{El}$ nuevo representante toscano, Francesco Giovanni de Médici, se hacía eco meses después de las continuas demandas de la priora. ${ }^{49}$ Finalmente, y tras mucho insistir, Mariana consiguió en abril de 1633 las deseadas pinturas (Goldenberg Stoppato 2013). La priora no perdió la oportunidad para agradecérselo al gran duque Fernando Il y de paso solicitar otras para el coro, además de «algunas libras de oro». ${ }^{50}$

\section{LA ENTRADA EN LA ENCARNACIÓN DE MUJERES DE LA FAMILIA MÉDICI}

En 1649, once años después de la muerte de Mariana de San José, profesó en el monasterio de la Encarnación una mujer con sangre real: Ana Margarita de Austria, hija natural de Felipe IV, quien acabaría convirtiéndose en subpriora (Sánchez Hernández 1997, 89 y 379)..$^{51}$ Este tema obsesionó a Mariana de San José, especialmente durante sus últimos años de vida, tal y como se desprende de su insistencia porque una mujer emparentada con la dinastía Habsburgo tomara los hábitos en su convento. En una carta que envió a María Magdalena en octubre de 1618, mencionaba que Felipe III había querido saber si enviaría a alguna de sus hijas al convento. ${ }^{52}$ En diciembre del mismo año, el nuevo embajador Giulio Inghirami contaba que la priora le había preguntado cuántas hijas tenían los Grandes Duques, sus edades y nombres, para acto seguido subrayar lo idóneo que sería que una de ellas tomase los hábitos en el monasterio..$^{53}$ En agosto de 1619 Giuliano de Médici informaba que la condesa de Barajas, María Sidona de Riederer, y la priora incidieron en la llegada de una de las niñas, a lo que el embajador respondió que eran demasiado jóvenes - Margarita tenía siete años y Ana solo tres-; además debían esperar a que alguna mostrase vocación. ${ }^{54}$ Mariana reconocía que se sentiría igualmente contenta si en lugar de una hija, la gran duquesa mandaba a una de sus hermanas:

Señora mía, aquí conviene mucho tener persona de Vuestra Alteza, digo de su casa y de su sangre, a quien se tenga respeto y amor. $Y$ en Su Alteza su hermana de Vuestra Alteza, que no sé el nombre, cabe todo esto; y en particular por el amor que el rey tuvo a su Majestad de la reina nuestra señora, y por el que tiene a esta casa, que también ayuda. ${ }^{55}$

48 ASF, MdP, 5080, f. 190, carta de la priora de la Encarnación al gran duque Fernando II, 17 de diciembre de 1631.

49 ASF, MdP, 5080, ff. 205; 324; 366 y 527.

50 ASF, MdP, 5080, f. 210, carta de la priora de la Encarnación al gran duque Fernando II, Madrid, 2 abril 1633.

51 Otra bastarda real, Margarita de Austria -hija natural de Juan José de Austria- pudo haber entrado en la Encarnación, si bien acabó profesando en las Descalzas tras la mediación de sor Ana Dorotea (Vilacoba Ramos 2005, 656).

52 «holgóse mucho el Rey en particular, y díjome que si traería aquí desde casa alguna hija que se holgaría de tener prenda tan cercana suya...». ASF, MdP, 6083, carta de la priora de la Encarnación a la archiduquesa, Madrid, 11 de octubre de 1618.

53 Carta del embajador Giulio Inghirami al secretario de la embajada Curzio da Picchena, 2 de diciembre de 1618, ASF, MdP, 4947, f. 94

54 ASF, MdP, 4949 f. 99, carta de Giuliano de Medici a Giulio Inghirami, 9 agosto 1619.

55 ASF, MdP, 6083, carta de la priora de la Encarnación a la archiduquesa, Madrid, 22 de enero de 1617.
Siguiendo la propuesta de la priora, una vez que la hermana de la gran duquesa se acostumbrase a la vida en la Encarnación, una de las hijas de María Magdalena podría seguir su ejemplo, un suceso para el que convenía no demorarse: «lo que importa es la brevedad de este negocio [...] será bien traer después una hija en que también importa echar aquí raíces, prendas de esa casa ${ }^{56}$ La hermana a la que se refiere es María Cristina de Austria, quien habitaba en una residencia para damas nobles de Hall (Graz) después de que en 1599 se anulara su traumático enlace con Segismundo Bathory, príncipe de Transilvania. El hecho de que circulasen rumores sobre la intención de María Cristina de viajar a Madrid para ingresar en las Descalzas Reales (Sanz Ayán 2012) pone de manifiesto la existencia de una posible rivalidad entre ambos conventos. La hipótesis de que se tratase de María Cristina queda confirmada en una misiva de Mariana fechada en mayo de 1621 en la que lamenta la muerte de Felipe III y de una de las hermanas de la gran duquesa, quien falleció el 6 de abril:

Y ahora débolo sentir más, pues teníamos ya llana la venida a esta casa, con que yo estaba consoladísima por ello y por el gusto que Su Alteza mostraba de venir, que fuera para mí el mayor consuelo que sabré decir tener aquí a quien servir, tan cercana deuda de la reina nuestra señora y de Vuestra Alteza.

No debemos olvidar que, además de la entrada de sor Margarita de la Cruz y sor Ana Dorotea en 1623, las Descalzas recibieron a Catalina d'Este el 15 de abril de 1621, hija de los duques de Módena Isabel y Alfonso d'Este y nieta de los duques de Saboya, Catalina Micaela y Carlos Manuel I. ${ }^{57}$ Según el embajador saboyano, su entrada fue propuesta por su tío, Filiberto de Saboya, ${ }^{58}$ imaginamos que con la intención de situar a personas de su confianza en estos espacios religiosos. La priora recurrió a la memoria de Margarita de Austria para conseguir su propósito, informando a principios de 1624 a María Magdalena de que la reina Isabel de Borbón «está con gran deseo de que Vuestra Alteza nos cumpla el que tenemos de darnos una prenda, que si mis ojos lo ven moriré contenta, pues veré lo que tanto deseó la reina nuestra señora, de tener aquí alguna persona de su casa y sangre». ${ }^{59}$

\section{¿RIVALIDAD ENTRE LA ENCARNACIÓN Y LAS DESCALZAS REALES?}

La defensa de los intereses habsbúrgicos es uno de los temas omnipresentes a lo largo de toda la relación epistolar entre María Magdalena de Austria y Mariana de San José. En la primera carta que se conserva de la priora de la Encarnación, esta asegura que «ayuda quanto puedo a las cosas de Alemania con amor y quydado que se debe siendo mis obligaciones. Su Magestad del emperador puede estar

\footnotetext{
56 ASF, MdP, 4949 f. 99, carta de Giuliano de Medici a Giulio Inghirami, 9 agosto 1619 .

57 Catalina falleció a principios de 1628 tras varios días negándose a comer. ASF, MdP, 4956, f. 27, carta de Averardo de Medici al secretario Cioli, Madrid, 26 de enero de 1628.

58 ASTo, Lettere Ministri, Spagna, 17, carta de Germonio Anastasio, Madrid, 14 de junio de 1620.

59 ASF, MdP, 6083, s.f., carta la priora de la Encarnación a la archi-
} duquesa, Madrid, 18 febrero 1624. 
cierto desto ${ }^{60}$ La priora había tratado estos temas con su hermano el archiduque Leopoldo, ${ }^{61}$ con quien mantuvo también correspondencia: ${ }^{62}$ "y a su Alteza del señor archiduque Leopoldo, aunque no lo sabe cómo mi contento está en servir, con eso queda satisfecha mi voluntad... ${ }^{63}$

Pero Mariana no se limitó a dejar constancia por escrito de su buena sintonía con la familia imperial. También intervino tratando de favorecer las negociaciones matrimoniales desarrolladas entre Florencia y Viena. La oportunidad surgió cuando en 1626 una hija del gran duque Fernando I, Claudia de Médici, se desposó con el archiduque Leopoldo. Desde 1620 existen noticias que sitúan a Mariana negociando este tema con el embajador alemán Khevenhüller. ${ }^{64}$ La priora volvería a inmiscuirse en los planes matrimoniales de los Médici apoyando los esfuerzos que María Magdalena realizó para obtener el consentimiento de Felipe IV del enlace de su segundogénito, Juan Carlos de Médici con Anna Carafa, heredera del principado de Stigliano. De su mediación dio testimonio el embajador toscano: "La Priora dell'Incarnazione ha fatto un bonissimo offizio con uno di questi signori del Consiglio di Stato. Et se potesse tanto quanto faceva a tempo di Filippo III, la Serenissima havrebbe una buona amica a Corte». ${ }^{65}$ La gran duquesa recurrió también a sor Margarita de la Cruz e incluso a la infanta María para que intercediesen ante el monarca católico, ${ }^{66}$ si bien resultaría infructuoso, pues la princesa contrajo matrimonio con el duque de Medina de las Torres, viudo de la única hija legítima del conde duque de Olivares. Felipe IV recompensó a Juan Carlos concediéndole el cargo de General de la Mar en 1638 y apoyando su elección como cardenal seis años más tarde.

La última carta que Mariana dirigió a María Magdalena está fechada unas semanas antes de la muerte de esta, el 12 de octubre de 1631. En ella le pedía que tuviese mucho cuidado en el viaje que había emprendido a Viena, en el que planeaba visitar a sus hermanos, el emperador Fernando y el archiduque Leopoldo (Menicucci 2008). Tras haber estado con este último en Innsbruck, la archiduquesa comenzó a sentirse mal y murió en Passau el 31 de octubre de 1631. Desconocedora de este fatal desenlace, la priora escribió a la archiduquesa reconociendo en su misiva su envidia «por poderlos ver y a su Magestad de la Reyna mi señora que me alegro imaginando el contento que tendrá Su Magestad con su compañía de V[uestra] A[Iteza] a quien suplico la

60 ASF, MdP, 6083, s.f., carta la priora de la Encarnación a la archiduquesa, Madrid, 22 enero 1617.

61 A ello alude Felipe III en respuesta a una misiva de la archiduquesa de marzo en la que le anunciaba la visita de su hermano. ASF, MdP, 6083, s.f., carta de Felipe III a la archiduquesa, Madrid, 8 de julio de 1618.

62 ASF, MdP, 4252, carta de Averardo de Medici a Curzio da Pichena, Madrid, 20 febrero 1623

63 ASF, MdP, 6083, carta de la priora de la Encarnación a la archiduquesa, Madrid, 19 septiembre 1618.

64 ASF, MdP 5079, f. 846, carta (cifrada) de Giuliano de Medici a Curzio da Picchena, Madrid 1 de mayo de 1620. Claudia de Medici (1604-1648) contrajo matrimonio en 1621 con Federico Ubaldo della Rovere, hijo del II duque de Urbino. Este falleció dos años después, dejando una hija: Vittoria, futura gran duquesa de Toscana. Tras su segundo enlace con Leopoldo, Claudia se trasladó a Innsbruck, donde desempeñó la regencia durante la minoridad de su hijo entre 1632 y 1646. Falleció dos años después.

65 ASF, MdP, 4958, s.f., carta de Michelangelo Baglioni a Andrea Cioli, Madrid, 27 febrero 1631.

66 ASF, MdP, 4958, 14 septiembre 1630. acompañe y entretenga algunos ratos por mí». ${ }^{67}$ Esta reina era la infanta española María de Austria, reina de Hungría y futura emperatriz, con quien la priora mantenía una fluida correspondencia epistolar, tal y como le reconoce en varias misivas a la gran duquesa. ${ }^{68}$

\section{MÁs allá de María Magdalena de Austria y de los INTERESES ALEMANES}

Mariana no dio por finalizado su intercambio con la familia granducal después de la desaparición de María Magdalena, dirigiéndose a partir de entonces al hijo de esta, el gran duque Fernando II. Se han conservado cinco cartas a él destinadas, incluida una copia traducida al italiano ${ }^{69}$ anterior a la muerte de su madre, la cual llevaba adjunta una serie de regalos que presumiblemente debían entregarse cuando esta regresara de su jornada imperial. ${ }^{70}$ Además de referirse a ella en las misivas que la priora envió al gran duque, Mariana se carteó directamente con la gran duquesa Vittoria della Rovere. Para esta última hemos encontrado cinco cartas: dos de ellas de mayo de 1636, otra fechada en el verano de 1637 y la última en marzo de 1638, tres meses antes de la muerte de la agustina recoleta. En la primera de ellas, Mariana agradece a la gran duquesa la carta recibida, reiterándole su amor y el de todas las monjas «... a tantos años que profeso en serlo de su Real Casa a que no faltava nunca la fidelidad de mi amor V[uestra] A[Iteza] me tiene siempre a sus pies y será gran favor que $V$ [uestra] A[lteza] me mande ${ }^{71}{ }^{71}$ Días después, Mariana escribe de nuevo a Vittoria della Rovere, si bien no encontramos las muestras de confianza que le profesaba a María Magdalena. Sí repite sin embargo su ofrecimiento para actuar como intermediaria ante la familia real, tal y como había hecho con la anterior gran duquesa: «me atrevo a suplicar se sirva de inviarme algunas niñerías para entretener a sus Altezas del príncipe y su hermana con las que me enviaban sus Altezas y príncipes de Vuestra Alteza se holgaban mucho sus majestades». ${ }^{72}$ Un año más tarde Mariana se excusa por no haber

\footnotetext{
67 ASF, MdP, 5080, f. 200, carta de la priora de la Encarnación a la archiduquesa, Madrid, 12 octubre 1631.

68 ASF, MdP, 5080, ff. 172-173, carta de la priora de la Encarnación a la archiduquesa, Madrid, 16 junio 1631. Unos meses antes la priora se quejaba de no haber recibido noticias de María Magdalena, solicitando noticias sobre la infanta María, con quien María Magdalena se había encontrado en Nápoles durante su jornada a Viena. ASF, MdP, 6072, carta de la priora de la Encarnación a la archiduquesa, Madrid, 26 octubre 1630.

69 La priora no hablaba ni leía italiano, de hecho, todas sus cartas están escritas en español. Gracias a una carta que Esaù del Borgo envía al Cioli, sabemos que pedía al primero le tradujese las misivas de la gran duquesa al castellano. ASF, MdP, filza 4958, s.f., Madrid, 31 de agosto de 1630. Ibídem, 2 de febrero de 1631. Lo mismo le pidió a Farncesco de Médici dos años después. ASF, MdP, 4959, f. 730, carta de Francesco de Médici a Andrea Cioli, Madrid, 19 de mayo de 1633.

70 ASF, MdP, 5080, f. 188, carta de la priora de la Encarnación a Fernando II, Madrid 29 de noviembre de 1631. En esta fecha la madre del gran duque ya había fallecido, pero la noticia aún no había llegado a Madrid.

71 ASF, MdP, 6147, f. 297, carta de la priora de la Encarnación a Vittoria della Rovere, Madrid 5 mayo 1636.

72 ASF, MdP, 6147, f. 298, carta de la priora de la Encarnación a
} Vittoria della Rovere, Madrid 7 mayo 1636. 
respondido a causa de su falta de salud y le envía unos obsequios cuya naturaleza desconocemos. ${ }^{73}$

De 1632 poseemos la única carta de la priora de la Encarnación a la gran duquesa Cristina de Lorena, aunque el hecho de que aluda a una misiva anterior permite intuir que existieron más. Mariana de San José se ponía a su servicio recordándole que siempre que podía mencionaba positivamente delante de los reyes a los Médici, solicitándole al finalizar la carta unos cuadros de Florencia. ${ }^{74}$ Tampoco en este caso encontramos las expresiones afectivas presentes en la correspondencia que la priora había mantenido con la archiduquesa, y aunque desconocemos cuándo se inicia este intercambio epistolar, indudablemente lo interpretamos como un intento de la priora porque el Gran Ducado de Toscana continuase favoreciéndola a ella y a su monasterio después del fallecimiento de María Magdalena.

\section{REFLEXIONES A PROPÓSITO DEL EPISTOLARIO DE MARIANA DE SAN JOSÉ}

El análisis de la correspondencia conservada de la priora de la Encarnación ha permitido dar respuesta a dos de las hipótesis de partida del presente trabajo. En primer lugar, demuestra cómo la Encarnación fue un espacio en el que circulaba información privilegiada, donde se trataron y negociaron asuntos políticos en los que participaron representantes de otras cortes europeas, rivalizando en este aspecto con las Descalzas Reales. En segundo lugar, a través del epistolario se ha podido profundizar en la figura de Mariana de San José, personaje extraordinario en las intrigas cortesanas que se desarrollaron en el tránsito del reinado de Felipe III al de su hijo Felipe IV. Como se apuntaba al inicio, no se trata de una figura desconocida, pues cuenta con numerosos estudios centrados en el análisis de sus obras, su labor como incansable reformadora de la orden agustina, así como en aspectos espirituales y cotidianos de su correspondencia. El propósito de estas páginas ha sido complementario al poner de relieve su función como mediadora política ante la familia real, una labor que desempeñó no solo ante agentes diplomáticos: también contó entre sus confidentes con personajes de la talla del príncipe Filiberto de Saboya o de los condes-duques de Olivares.

En este sentido, resulta de enorme interés la participación de la priora en diversas conspiraciones organizadas por los núcleos de oposición contrarios a los respectivos validos durante el reinado de Felipe III, entre ellas la gestada contra Lerma, o la fallida liderada en 1620 por el príncipe Filiberto de Saboya que buscaba la destitución del confesor fray Luis de Aliaga y el duque de Uceda. Es así mismo característico que siempre formase parte del mismo grupo en el que se encontraba sor Margarita de la Cruz, a pesar de que como se ha demostrado existieron rencillas entre ellas. El hecho de que ambos espacios religiosos femeninos -las Descalzas y la Encarnación- actuasen como lugares de encuentro para tertulias políticas no pasó desapercibido para la Corona, que no vio con buenos ojos estas acciones.

\footnotetext{
73 ASF, MdP, 6148, s. f., carta de la priora de la Encarnación a Vittoria della Rovere, Madrid 14 julio 1637.

74 ASF, MdP, 5977, f. 254, carta de la priora de la Encarnación a la gran duquesa Cristina de Lorena, septiembre 1632.
}

Así entendemos la intervención del conde duque de Olivares en una sesión del Consejo de Estado unos días después de la muerte de sor Margarita en 1633, en la que solicitaba que se impidiese que sor Ana Dorotea, monja profesa en las Descalzas e hija natural del emperador Rodolfo II, recibiese las visitas de embajadores y otras personas. Gaspar de Guzmán finalizaba su intervención aconsejando que se hiciese lo mismo en la Encarnación: «Y con esta ocasión ha parecido al conde representar a VM que sería bien que se advirtiese a la Priora de la encarnación que no reciba visitas de embaxadores un consienta que lo haga ninguna otra monja...", postura que fue aceptada por el resto de los asistentes en el Consejo de Estado. ${ }^{75} \mathrm{El}$ valido, no pudiendo controlar lo que sucedía en el interior de esos muros, debía temer que el convento organizara un grupo de oposición a su figura tal y como había sucedido con su antecesor treinta años antes. En este sentido no podemos dejar de preguntarnos cuál fue el posicionamiento de Mariana de San José ante el valimiento de Olivares, y cómo se debe interpretar la relación que desarrolló con este y con su mujer, amiga de la priora según el nuncio. Fernando Negredo (2006, 376-377) afirma que uno de los religiosos contrarios al valido, el jesuita Herrera, estuvo muy vinculado a la Encarnación y las Descalzas. Desafortunadamente, la ausencia de testimonios documentales nos impide considerar a las Descalzas o a la Encarnación focos de oposición a Gaspar de Guzmán. Diversos estudios han apuntado a que un núcleo de religiosos -entre los que figuraba el confesor del rey (Filippini 2006) - maniobró en la destitución del conde duque a comienzos de 1643; si bien tanto sor Margarita como Mariana habían fallecido años antes. Son muchos los interrogantes que quedan en el aire, pues la correspondencia de Mariana de San José está incompleta y -salvo las excepciones que suponen los borradores de cartas - solo se conserva el testimonio de uno de los dos sujetos que interactuaron a través del papel. Lo que la documentación sí nos ha permitido probar ha sido la excepcionalidad de la figura de Mariana de San José, así como sus esfuerzos porque el monasterio de la Encarnación alcanzase el rango privilegiado que ostentaba las Descalzas Reales.

\section{BiBLIOGRAFÍA}

Alonso O.S.A. 1988. "Cartas de la Madre Mariana de San José y otras prioras del Monasterio de la Encarnación de Madrid a los Barberini». Recollectio: annuarium historicum augustinianum 11: 565594.

Álvarez, Arturo. 1971. "Curioso epistolario en torno a la infanta sor Margarita de la Cruz». Hispania Sacra 24: 187-225.

Anselmi, Alessandra. 2014. "Antiveduto Grammatica, Cassiano dal Pozzo e Vittorio Amedeo di Savoia: un dono per Margarita de la Cruz e un problematico, inedito, Sant'Agostino nelle Descalzas Reales di Madrid. Tra politica e devozione, l'espressione degli affetti». En I rapporti tra Rome e Madrid nei secoli XVI e XVII: arte, diplomazia e politica, edición de Alessandra Anselmi. Roma: Gangemi.

Antolín Rejón, Carlos. 2016. "El complejo rol dinástico de un hijo segundón: el príncipe Emanuele Filiberto de Saboya (1588-1624) ¿Mediador, embajador familiar o agente doble?». En III Encuentro de Jóvenes Investigadores en Historia Moderna. Familia, cultura material y formas de poder en la España Moderna, edición de

75 Consulta del Consejo de Estado, Madrid, 17 de julio de 1633. AGS, Estado, leg. 2652, s. f. 
Máximo García Fernández. Madrid: Fundación Española de Historia Moderna.

Arrivo, Georgia. 2007. «Una dinastia al femminile. Per uno sguardo diverso sulla storia político-istituzionale». En Carte di donne. Per un censimento regionale della scrittura delle donne dal XVI al XX secolo, vol. II, edición de Alessandra Contini y Anna Scattigno, 4957. Roma: Edizioni di Storia e Letteratura.

Atienza, Ángela. 2008. Tiempo de conventos: una historia social de las fundaciones en la España moderna. Madrid: Marcial Pons.

Baranda Leturio, Nieves y María Carmen Marín Pina, eds. 2014. Letras en la celda. Cultura escrita de los conventos femeninos en la España moderna. Madrid - Frankfurt am Main: Iberoamericana - Vervuert.

Belardini, Manuela. 1999. «"Piace molto a Giesù la nostra confidanza”. Suor Orsola Fontebuoni a Maria Maddalena d'Austria ». Per lettera. La scrittura epistolare femminile tra archivio e tipografia, secoli XV-XVII, edición de Gabriella Zarri, 359-383. Roma: Viella.

Carlos Varona, María Cruz. 2007. «Representar el nacimiento: imágenes y cultural material de un espacio de sociabilidad femenina en la España Altomoderna». Goya 319: 231-245.

Carlos Varona, María Cruz y Peter Cherry. 2020. «Jugando con Baltasar Carlos. Arte y cultura material en la educación del príncipe». La mirada extravagante: arte, ciencia y religión en la Edad Moderna, edición de María Cruz de Carlos Varona, Felipe Pereda y José RieIlo, 273-337. Madrid: Marcial Pons.

Castillo Gómez, Antonio. 2014. "Cartas desde el convento. Modelos epistolares femeninos en la España de la Contrarreforma». Cuadernos de Historia Moderna XIII: 141-168. https://doi.org/10.5209/ rev_CHMO.2014.46795

Checa Cremades, Fernando. 2019. "La otra Corte. Piedad femenina y gusto cortesano en los monasterios reales de las Descalzas y la Encarnación de Madrid». En La otra Corte. Mujeres de la Casa de Austria en los Monasterios Reales de las Descalzas y la Encarnación, edición de Fernando Checa Cremades, 15-41. Madrid: Museo del Prado.

Cruz, Anne J. 2014. The life and writings of Luisa de Carvajal y Mendoza. Toronto: Centre for Reformation and Renaissance Studies.

Cruz, Anne J. 2019. "Más allá de las rejas: las redes nobiliarias mujeriles y el patronazgo conventual». En Identità nobiliare tra Monarchia Ispanica e Italia. Lignaggi, potere e istituzioni (secoli XVI-XVIII), edición de Carmen Sanz Ayán, Santiago Martínez Hernández, Marcella Aglietti y Daniele Edigati, 205-218. Roma: Edizioni di Storia e Letteratura.

Díez Rastrilla, Jesús. 2014. Obras Completas de la madre Mariana de San José. Madrid: Biblioteca de Autores Cristianos.

Elliott, John. 2010. El conde-duque de Olivares. El político en una época de decadencia. Barcelona: Crítica.

Filippini, Orietta. 2006. La conscienza del Re. Juan de santo Tomás, confessore di Filippo IV di Spagna (1643-1644). Florencia: Leo S. Olschki Editore.

Franganillo Álvarez, Alejandra. 2013. «Diplomacia formal e informal. Noticias y regalos en torno a la princesa Isabel de Borbón (16151621)». En En tierras de confluencias. Italia y la Monarquía de España (siglos XVI-XVIII), edición de Cristina Bravo Lozano y Roberto Quirós Rosado, 128-141. Valencia: Albatros Editores.

Franganillo Álvarez, Alejandra. 2019. «Intereses dinásticos y vínculos familiares. La red epistolar transnacional de la Gran Duquesa María Magdalena de Austria (1608-1631)». En De puño y letra. Cartas personales en las redes dinásticas de la Casa de Austria, edición de Bernardo García García, Andrea Sommer-Mathis y Katrine Keller, 173-200. Madrid - Frankfurt: Iberoamericana - Vervuet.

Galli Stampino, Maria. 2013. "Maria Maddalena, Archduchess of Austria and Grand Duchess of Florence: negotiating performance, tradition and taste». En Early Modern Habsburg Women. Transnational Contexts, Cultural Conflicts, Dynastic Continuities, edición de Anne J. Cruz y Maria Galli Stampino, 41-56. Farnham - Burlington: Ashgate.

García-Frías Checa, Carmen. 2019. "Las galerías de retratos de las Descalzas Reales y de la Encarnación: un signo de pertenencia a la Casa de Austria». En La otra Corte. Mujeres de la Casa de Austria en los Monasterios Reales de las Descalzas y la Encarnación, edición de Fernando Checa Cremades, 212-227. Madrid: Museo del Prado.
García García, Bernardo J. 1997. «Honra, desengaño y condena de una privanza. La retirada de la corte del Cardenal Duque de Lerma». En Monarquía, Imperio y pueblos de la España Moderna, Actas de la IV Reunión Científica de la Asociación Española de Historia Moderna, coordinación de Pedro Fernández Albadalejo, vol. I, 679-695. Alicante: Caja de Ahorros del Mediterráneo.

García García, Bernardo J. 2020. «Felipe III y la pacificación de Italia (1612-1618)». En El Piamonte en Guerra (1613-1659). La frontera olvidada, edición de Bernardo J. García García y Davide Maffi, 2157. Madrid: Doce Calles - Fundación Carlos de Amberes.

García Prieto, Elisa. 2016. «Fue la reina a las Descalzas. Vínculos familiares y construcción del espacio cortesano en la década de 1570». En Felix Austria. Lazos familiares, cultura política y mecenazgo artístico entre las cortes de los Habsburgo, edición de Bernardo J. García García, 375-392. Madrid: Fundación Carlos de Amberes.

Geebers, Lisbeth. 2016. "Dynasty and State Building in the Spanish Habsburg Monarchy: The career of Emanuele Filiberto of Savoy (1588-1624)». Journal of Early Modern History 20: 267-292. https://doi.org/10.1163/15700658-12342512

Goldenberg Stoppato, Lisa. 2004. "Per Domenico e Valore Casini, ritrattisti florentini». Mitteilungen des Kunsthistorischen Institutes in Florenz 48 (1/2): 165-210.

Goldenberg Stoppato, Lisa. 2013. "“Et qui si stimano i regali quanto a Costantinopoli": doni per il monastero dell' Encarnación e la diplomacia Medicea a Madrid». En L'arte del dono. Scambi artistici e diplomacia tra Italia e Spagna, 1550-1650, edición de Marieke von Bernstorff e Susanne Kubersky-Piredda. Milano: Silvana Editoriale. Guzmán, Diego de. 1617. Reyna Católica. Vida y muerte de D. Margarita de Austria reyna de España. Madrid: por Luis Sánchez.

Keller, Katrine. 2019. "The Archduchess, the Queen, a jesuit and a carintian noblewoman: the correspondence of Mary of Styria (1551-1608) with the Spanish court». En De puño y letra. Cartas personales en las redes dinásticas de la Casa de Austria, edición de Bernardo García García, Andrea Sommer-Mathis y Katrine Keller, 147-171. Madrid - Frankfurt: Iberoamericana - Vervuet.

Kettering, Sharon. 1986. Patrons, brokers, and clients in seventeenth century France. New York - Oxford: Oxford University Press.

Lavrín, Asunción. 1995. «De su puño y letra. Epístolas conventuales». En El monacato femenino en el imperio español. Monasterios, beaterios, recogimientos y colegios, coordinación de Manuel Ramos Medina, 43-61. México D.F.: Condumex.

Marcos Sánchez, Mercedes. 2018. "Crónicas, biografías y hagiografías». En Las escritoras españolas de la Edad Moderna. Historia y guía para la investigación, edición de Nieves Baranda Leturio y Anne Cruz, 98-111. Madrid: UNED.

Marek, Pavel. 2011. "Luisa de las Llagas. La abadesa de las Descalzas y el proceso de comunicación política y cultural entre la corte real española y la imperial». Pedralbes 31: 47-90.

Martelli, Francesco y Cristina Galasso, ed. 2007. Istruzioni agli ambasciatori e inviati medicei in Spagna e nell'Italia spagnola (15361648). Roma: Ministerio per i Beni e le attività cultural.

Menicucci, Roberta. 2008. «ll viaggio di Maria Maddalena a Vienna: politica e cerimoniale». En Le donne Medici nel sistema Europeo delle corti XVI-XVIII secolo, edición de Giulia Calvi y Riccardo Spinelli, tomo I, 269-282. Firenze: Edizioni Polistampa.

Muñoz, Luis. 1646. Vida de la venerable madre Mariana de San Joseph fundadora de la Recolección de las Monjas Agustinas Priora del convento de la Encarnación. Madrid.

Negredo del Cerro, Fernando. 2006. Los predicadores de Felipe IV. Corte, intrigas y religión en la España del Siglo de Oro. Madrid: Actas.

Poutrin, Isabelle. 1995. Le voile et la plume. Autobiographie et sainteté féminine dans l'Espagne moderne. Madrid: Casa de Velázquez.

Rainer, Johann. 2005. "Tú, Austria feliz, cásate. La boda de Margarita, princesa de Austria interior, con el rey Felipe III de España, 15981599». Investigaciones Históricas: Época Moderna y Contemporánea 25: 31-54.

Río Barredo, María José del. 2006. «El viaje de los príncipes de Saboya a la corte de Felipe III (1603-1606)». En L' affermarsi della corte sabauda. Dianstie, poteri, élites in Piemonte e Savoia fra tardo Medievo e prima età moderna, edición de Paola Bianchi y Luisa Clotilde Gentile, 407-434. Torino: Silvio Zamorani. 
Sánchez, Magdalena. 1993. «Confession and Complicity: Margarita de Austria, Richard Haller, S.J., and the Court of Philip III». Cuadernos de Historia Moderna 14: 133-149.

Sánchez, Magdalena. 1998. The Empress, the Queen, and the Nun. Women and power at the Court of Philip III of Spain. Baltimore: Johns Hopkins University Press.

Sánchez, Magdalena. 2009. "Privacy, family and devotion at the Court of Philip II». En The Politics of Space: European Courts, cs. 15001750, edición de Marcello Fantoni, George Gorse y Malcolm Smuts, 361-381. Rome: Bulzoni Editore.

Sánchez Hernández, María Leticia. 1997. Patronato regio y órdenes religiosas femeninas en el Madrid de los Austrias: Descalzas Reales, Encarnación y Santa Isabel. Madrid: Fundación Universitaria Española.

Sánchez Hernández, María Leticia. 2011. «Vida cotidiana y coordenadas socio-religiosas en el epistolario de Mariana de San José (1603-1638)». En Memoria e comunità femminili: Spagna e Italia, secc. XV-XVII, edición de Gabriella Zarri y Nieves Baranda, 88-109. Florencia: Firenze University Press.

Sánchez Hernández, María Leticia. 2014. "Servidoras de Dios, leales al Papa. Las monjas de los monasterios reales». Libros de la Corte 1 (6): 309-314. https://revistas.uam.es/librosdelacorte/article/ view/1636

Sanz Ayán, Carmen. 2012. "Elementos para la construcción de la imagen ideal de un príncipe cristiano "de Frontera": Segismundo
Bathory, Príncipe de Transilvania». Hispania Félix: Revista HispanoRumana de Cultura y Civilización de los Siglos de Oro 3: 213-248.

Terrasa Lozano, Antonio. 2014. «Comercio ultramarino, corporación jurídica y tramas de poder e influencia en el Asia luso-castellana: el viaje del monasterio de la Encarnación (1611-1636)». Minius 22: 193-224.

Toajas Roger, M. Ángeles. 2016. «Palacios ocultos: las Descalzas Reales de Madrid». En Felix Austria. Lazos familiares, cultura política y mecenazgo artístico entre las cortes de los Habsburgo, edición de Bernardo García García, 329-374. Madrid: Fundación Carlos de Amberes.

Vilacoba Ramos, Karen. 2005. "Entre Dios y la Corona: relaciones epistolares de sor Ana Dorotea de Austria con Felipe IV». En El franciscanismo en la península ibérica, balance y perspectivas: I Congreso Internacional, coordinación de María del Mar Graña Cid y Agustín Boadas Llavat, 643-662. Barcelona: GBG Editora.

Volpini, Paola. 2016. "Sorelle, granduchesse e regine nel primo Seicento.Origini asburgiche, connessioni politiche e reti di rapporti fra corte di Toscana e corte di Spagna». En Élites internazionali e reti di potere. Strategie d'integrazione nell'Europa di età moderna, edición de Marcella Aglietti, Alejandra Franganillo y J. Antonio López Anguita, 119-132. Pisa: Pisa University Press.

Zarri, Gabriella, ed. 1999. Per lettera. La scrittura epistolare femminile tra archivio e tipografia: secoli XV-XVII. Roma: Viella. 